\title{
EVOLUTION OF TROLLEY-BUS: DIRECTIONS, INDICATORS, TRENDS
}

\author{
Serhii HUTYRIA, Andriy CHANCHIN, Viktor YAGLINSKYI, \\ Yuriy KHOMIAK, Vadym POPOV
}

Odessa National Polytechnic University, Odessa, Ukraine, e-mail: hutyria@opu.ua

\begin{abstract}
Focus of customers only on the best model' parameters of urban wheel transport with electric drive (trolley-, electric- and hybrids) presented at the world market today leads to objective lag minimum in five and more years from the achievable technical/technological world level. This paper targeted to create on example of serially made trolley-bus ( $T$-bus) models an objective dataset for determining and extrapolation the trends of its perfection physically informative indicators. The consecutive application of the ordinary least squares method and modified Kendall-Theil robust method to small selections of the offered indicator' trends received. Reasonable by the theory of similarity and dimensional analysis the model' structure and the kernel of perfection level index obtained and characterized by the possibility of its periodic upgrading in accordance with the customers and designers requirements. The classification of the drive axle generations in electric drive traction transmissions, considers analysis of its structure and construction's elements, proposed. On example of the known traction transmissions' structures the circuit-logical technique of taking notes its reliability at express diagnostics of the certain $T$-bus model perfection level developed. Further increasing of some numeric markers of energy efficiency, load capacity, comfort, ergonomics and operational reliability of the $T$-buses by adequate linear trends is confirmed. Accented, that the open access to the dataset of the vehicle' perfection level indicators is one of the foremost challenges in methodology of its $C A E$-methods optimal design and have practical significance to improve such products.
\end{abstract}

Key words: vehicle' model perfection level, diagnostics, physically informative indicators, traction transmission reliability

\section{HIGHLIGHTS}

- New methodology for determine the set of objective physically informative indicators for the $T$-bus' model perfection level is proposed.

- Open access dataset of the $T$-bus models technical/technological perfection' indicators created, corresponding evolution trends for serially made $T$-buses obtained.

- An original model for diagnostics of the $T$-bus design perfection level developed and its kernel by the theory of similarity and dimensional analysis proved.

- New classification of the drive axle' generations and the circuit-logical technique of the traction transmissions reliability diagnostics proposed.

\section{NOMENCLATURE AND GLOSSARY}

$a, b, c \quad$ exponents for independent variables

$g \quad$ acceleration of gravity, $\mathrm{m} / \mathrm{s}^{2}$

$J_{S} \quad$ seat's capacity of $T$-bus

$J_{\Sigma} \quad$ total passengers capacity

$k \quad$ constant coefficient

$L_{p R} \quad$ normative noise level in inside of

reference vehicle, dBA

$L_{p A} \quad$ noise level in inside of evaluated vehicle, dBA

$L_{T} \quad$ average lifetime distance of the $T B, \mathrm{~km}$

$L_{W} \quad$ manufacture' warranty, years
$m_{\Sigma} \quad$ mass of loaded vehicle, $\mathrm{t}$

$N_{\Sigma} \quad$ total capacity of installed TEM, $\mathrm{kW}$

$n \quad$ space dimension of vehicle' technical/technological perfection indicators

$P_{j} \quad$ probability of failure-free operation the system' element $j$

$P_{S R} \quad$ reliability index value of reference system

$P_{S T} \quad$ reliability index of the evaluated system

$Q_{j} \quad$ system' element $j$ probability of failure

$q_{j} \quad$ dimensionless indicator $i$ of perfection

$R^{2} \quad$ regression metrics

$R_{t c} \quad$ turning circle radius, $\mathrm{m}$

$T_{j} \quad$ load torque, $\mathrm{kN} \cdot \mathrm{m}$

$t \quad$ model year of evaluated sample

$u \quad$ gear ratio

$V_{\max }, \quad$ maximal speed of $T$-bus with network

$V_{a m} \quad$ mode operation and in autonomous

mode, $\mathrm{km} / \mathrm{h}$

$W_{\max } \quad$ maximum acceleration of $T$-bus, $\mathrm{m} / \mathrm{s}^{2}$

$\gamma$

index of perfection and its values in the

$\gamma^{\prime}, \gamma^{\prime \prime} \quad$ first and the second approaches

$\eta \quad$ mechanical effectiveness

$\Omega \quad$ set of physically informative parameters and characteristics

$A M-W \quad$ aggregated motor-wheel

$A T V S$ active torque vectoring system

$C A E \quad$ computer-aided engineering 


$\begin{array}{ll}C N G & \text { ICE with gas fuel } \\ D & \text { diesel, } D \text {-drive, } D \text {-bus } \\ D A & \text { drive axle } \\ D-G & \text { diesel-generator } \\ D S H & \text { hybrid bus with } D \text { - } G \\ E & \text { electric bus, } E \text {-drive, } E \text {-bus } \\ E M D & \text { electromechanical inter-axial } \\ F C & \text { differential } \\ G R E E T & \text { fuel cell } \\ & \text { greenhouse gases, regulated emissions } \\ I C E & \text { and energy use in transport } \\ I G B T & \text { internal combustion engine } \\ I H G & \text { insulated-gate bipolar transistor } \\ I M-W & \text { integrated motor-wheel } \\ K T R M & \text { Kendall-Theil robust method } \\ M D & \text { mechanical differential } \\ M-G & \text { motor-generator } \\ M T G & \text { multi-threaded gear } \\ O L S M & \text { ordinary least squares method } \\ P W G & \text { planetary wheel gear } \\ T B & \text { traction battery } \\ T E M & \text { traction electric motor } \\ T S C & \text { traction super capacitor } \\ T T & \text { traction transmission }\end{array}$

\section{INTRODUCTION}

At beginning of the XXI century the demand for using the electric drive (E-drive) at solution of economic and environmental problems, caused by internal combustion engines (ICE), has increased substantially. The wheel transport world market promptly changes towards increase in a segment of models with hybrid and full $E$-drive (fig. 1) [31].

The forecast of the Institute for Energy Research, USA, 2014, on the 2022 and the next years have been used such guideline:

- Buses with ICE, series hybrids with dieselgenerator $(D-G)$ and parallel hybrids (duobuses), as a product in the market fall stage.

- Urban $T$-buses and series hybrids capable of operating from the contact network and autonomy with dynamic recharge in the limits of a city cycle in proportion on a run up to 50:50, as a product in the market mature stage.

- Plug-in full E-buses (without generator) and series hybrids using two/three autonomy energy sources (motor-generator $M-G$, recharged traction batteries $T B$, traction super capacitors $T S C$, fuel cells $F C$ ), as a product in the market development stage.

Today, the forecast come true, thanks to the accelerated development of new branch of components for $E$-drive and alternative energy sources. The percentage of purely $E$-power urban wheel transport will be increasing, with this heavily dependent on the development of mobile energy storage systems and the associated energy chain and infrastructure.
None of the mentioned concepts is far "the best" therefore, in the near future (2025...2035) hypothetically can apply for the leading positions every $E$-drive hybrid with alternative energy sources, including contact network, TB, TSC, FC, $M-G$ with gas fuel (metan) etc.

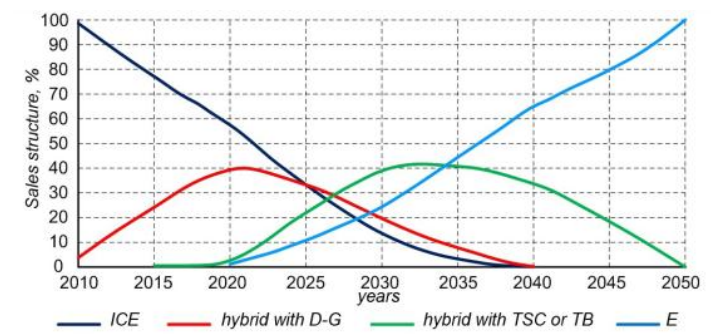

Fig. 1. Forecast of sales structure in USA of wheel transport with various types of drive and energy generation [31]

First of all this are highly effective traction electric motors (TEM) of alternating current on permanent magnets, compact and economic inverters of the electric power on semiconductors, electric power capacitors on base of Li-ion rechargeable $T B, T S C$ and multilevel intellectual control systems combinations. The TEM typically is more durable than the ICE and cause less secondary damage from vibration, so the $T$-buses tend to be long-lived compared to the $D$ - ones. The main advantages of the $E$-drive application display the following indicators:

- The environmental friendliness - by Euro-5 standards the $E$-drive compared to the $D$ - one is significantly better (table 1) [25, 30]. Also the lack of exhaust allows the $T$ - and $E$-buses to operate and stop in underground locations.

- The energy efficiency of the $E$-drive provides minimum level of energy consumption (fig. 2) [28]. According the dataset of Solaris Corporation the power consumption at operation of standard $12 \mathrm{~m} \mathrm{E}$-bus is up to $2.52 \mathrm{kWh} / \mathrm{km}$ that it is less compared to the $D$ - one for $43 \%$ and respectively for $29 \%$ compared to hybrid one with the $D-G$ in identical service conditions [11].

\begin{tabular}{|c|c|c|c|c|c|}
\hline $\begin{array}{c}\text { Table 1. } \\
\text { Indicators of } \\
\text { environmental } \\
\text { friendliness of } \\
T \text {-bus and } D \text { - } \\
\text { busPollutants }\end{array}$ & $\begin{array}{c}\text { Local emissions, } \\
\mathrm{g} / \mathrm{km}\end{array}$ & \multicolumn{3}{c|}{ Global emissions, g/km } & \\
\cline { 2 - 6 } & $T$-bus & $D$-bus & & & \\
\hline $\mathrm{SO}_{2}$ & 0 & 1.07 & 0.86 & 0.43 & 1.7 \\
\hline $\mathrm{NO}_{2}$ & 0 & 23.6 & 1.31 & 0.66 & 24.2 \\
\hline $\mathrm{CO}$ & 0 & 0.47 & 0.61 & 0.31 & 4.8 \\
\hline $\mathrm{CO}_{2}$ & 0 & 1204 & 912 & 456 & 1314 \\
\hline Soot & 0 & 0.47 & 0.25 & 0.13 & 0.5 \\
\hline $\begin{array}{l}\text { Note. Electricity is produced at power stations: } \\
\text { hydroelectric }\end{array}$ & & & & \\
\hline
\end{tabular}

High energy efficiency due to higher efficiency of the TEM and the possibility of energy recovery to the electric network or $T B$ (up to $20 \%$ ) with electrodynamics braking [11]: 


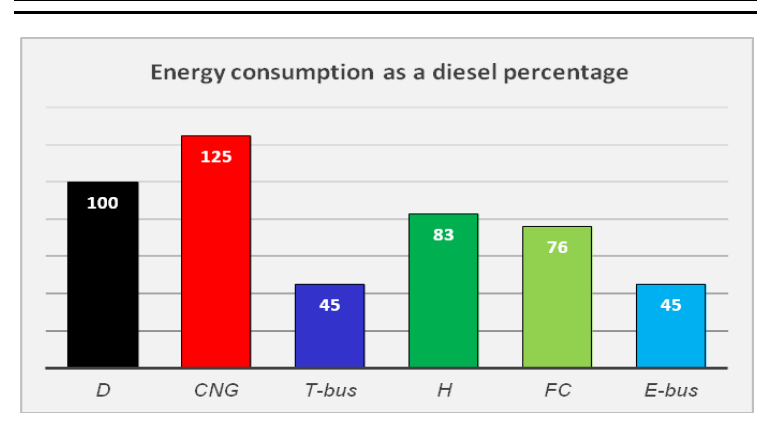

Fig. 2. Power drive energy consumption comparison [28]: $D$ - diesel; $C N G$ - ICE with gas fuel; $H$-hybrid average; $F C$ - hybrid with fuel cells

- Noise pollution - unlike trams, the gasolineand $D$-buses, the $T$ - and $E$-buses are almost silent, lacking some noise of an ICE or wheels on rails. According to the results of the "TROLLEY project" for the Central Europe (Poland, Czech Republic, Slovakia, Austria, Hungary, Slovenia, Germany, Italy and Ukraine) significantly lower values of the $E$-drive acoustic emission to the environment (up to $10 \ldots 18 \mathrm{dBA}$ ) in comparison with the $D$ - one by experiments proved [28, 31].

- Useful ability of the $E$-drive to overcome steep rises (up to $12 \%$ ), especially in winter, when used in cities with allowed speed up to $50 \mathrm{~km} / \mathrm{h}$.

- Using the $T$-bus for running the dedicated roadways or the claimed by the Siemens Corporation optical guidance system give the ability to maintain higher speeds on very narrow corridors and to automatically dock at curved stops with a better than $50 \mathrm{~mm}$ gap at the platform.

To build up a time-dependent evaluation model, describing the impact of the $E$-drive vehicles popularity on the following four aspects: the total amount of pollution produced by all vehicles in traffic, the production cost of vehicles, the efficiency of public transportation and the total amount of energy required by all vehicles on streets is aimed $[21,36]$.

To overcome the known $T$-bus technology' drawbacks (insufficient maneuverability, infrastructure' high cost and negative influence of electric networks on the aspect of streets intersections often have a "webbed ceiling" appearance, due to multiple crossing and converging sets of wires) the leading world manufacturers initiated production, capable of operating autonomy with dynamic recharging from contact networks that ensures their maneuverability approaching the urban' bus level.

In Germany, May 2019, started the E-autobahn intended for the movement of cargo truck-hybrids with dynamic recharge of $T B$ from the contact network [20]. The site of $5 \mathrm{~km}$ long between the airport of Frankfurt and industrial park near Darmstadt is open for tests. It is expected that 40tones truck-hybrids will be able to save on fuel to 20.000 Euros at a run 100 thousand km. Project
"Elisa" is developed by the Siemens Corporation, the similar projects also kept by the BMW Corporation.

The new models of $T$-buses and hybrids with dynamic recharge are equipped with some of the following autonomous power sources: the $T B$ (Li-ion or nickel-metal hydride Ni-MH, energy density up 320 $\mathrm{kWh}$, course stock of 10 to $40 \mathrm{~km}$, manufacture warranty up to $8 \ldots 10$ years or $150 \ldots 200$ thousand $\mathrm{km}$ ) and/or the $T S C$ with high power density charging.

Today, about 300 T-buses' contact networks in 47 countries operated, most of them are located in Europe, South America and Asia. The famous transnational corporations of the $T$ - and $E$-buses serial production are located in Germany, Switzerland, Belgium, France, Italy, Poland, Czech Republic, Canada, China, Ukraine and Belarus.

In Ukraine urban $E$-drive transport traditionally plays an important role. At present its share is $42 . .56 \%$ of the total volume of passenger traffic and in regional centers - up to $60 \%$.

As the main component of competitiveness of the passenger vehicle in the world market are recognized its technical/technological level (hereinafter the perfection level) and quality of serially made production, which are in a complex reflecting extent application of the latest scientific and innovation developments in design and manufacture. The certain vehicle' model perfection level is determined by the comparison values of its perfection' indicators relatively the reference sample.

Customers, designers and operating companies are extremely interested in objective information about the perfection level of the $T$ - and $E$-bus' models available in the world market because of their high cost, intensive operating conditions, significant periods of use and depreciation. Such information should contain steady in time set of limited number indicators, facilitating the certain model reasonable choice when ordering, scheduling maintenance intervals and determining effective directions to extend the periods of reliable operation [4, 23]. As is known, because of the intense competition between producers, much of this information, in particular regarding operational reliability, has very limited access, that's a technical secret.

The purposes of this study are:

- To form an open access dataset of objective physically informative indicators the $T$-bus design technical/technological perfection, determine and confirm statistically the stability of the corresponding trends.

- To develop and prove the model structure of the perfection level index of the $T$-buses, allowing its specification and expansion taking into account the main requirements of customers, designers and manufactures.

- To develop a technique of accounting of aprioristic reliability of units, modules and other 
"criteria elements" of the $T$-bus system at express-diagnostics the certain model perfection level.

\section{MAIN FEACHERS OF T-BUS' EVOLUTION}

From analysis of the online available open access information established that the $T$-bus' today production characterized by some organization feathers and technical/technological trends, namely:

- Creation of joint transnational corporations in order to concentrate financial and other resources by application of innovative technologies and upgrading of produced models for expansion of sale markets.

- Unification of produced urban $T$ - and $E$-bus' models along the length (size $12 \mathrm{~m}$ is defined as standard, $8 \ldots 11 \mathrm{~m}-$ as midi, > $18 \mathrm{~m}-$ as large).

- Expanding the manufacturing of large models provides improved its profitability by unifying components and equipment, reducing the complexity of technological processes and operating costs.

- Development of new models with multiarticulated body as the most efficient regards the passenger traffic on urban and suburban routes.

- For use in the central part of megacities continued manufacturing of midi models with the classic wagon configuration.

- Transition since 1995 to the manufacturing of models only with low floor or low entry provides the level $320 . .350 \mathrm{~mm}$ of the first step above the ground, the possibility of kneeling at stops, increased comfort and the average speed of transportation up to $40 \%$.

- Preferentially use of asynchronous TEM with two typical control systems - pulse and IGBT based, that saves up to $40 \%$ of electric power and provide reduction in the shock load on the traction transmission (TT).

- Transition since 2010 to the manufacturing the $T$-bus models with the $T B$ and/or the $T S C$, providing its autonomy at level $10 \ldots 20 \mathrm{~km}$ at an average speed of $15 \ldots .20 \mathrm{~km} / \mathrm{h}$.

- Initiated since 2013...2015 the manufacturing of the $T$-buses and cargo hybrids capable of operating autonomy with dynamic recharge from contact networks, that ensure their maneuverability approaching the $D$-bus level at urban routes.

- Deepening unification of all models by component systems, units and modules namely: the frontal and back pendants have become exclusively spring-pneumatic, the steering received hydraulic amplifier, drives that enable optimum use of space and a high degree of maneuverability, such as the wheel-hub drive, are taking center stage, etc.

The certain feathers and trends of the $T$-bus evolution determine corresponding requirements for its main subsystems, firstly - the $T T$ structure and design systematically associated with the relevant indicators of energy efficiency, environmental friendliness, ergonomics and operational reliability, maintenance and repair costs.

By the method of energy transformation and power transmission, most of the $T T$ structures in the $T$-bus' models are electromechanical, which in comparison with mechanical or hydro-mechanical ones characterized by the following advantages:

- Free choice of wheel formula and simplicity of circuit layout for various types of electric transport with lowered floor level.

- Greater reliability and regulatory durability due to less complex design (no clutch and gearbox).

- Higher maneuverability, traction and dynamic characteristics, providing for articulated-body $T$ buses with increased passenger capacity thanks to application of two drive axles $(D A)$, smooth adjustment of traction force, relative simplicity of automation control systems and active safety.

- Higher energy efficiency due to minimal energy losses in the process of transformation, transmission to the driving wheels and electrodynamic energy recovery during braking.

- Lower costs for manufacturing, operation and maintenance.

At the same time, the electromechanical TT has some disadvantages in comparison with the electric one:

- Larger mass of the constituent units, modules and mechanisms, which requires additional measures for vibration isolation.

- A priori smaller operational reliability of the $T T$ system consisting of some elements and connections, which are oscillated, worn out and heated during the work.

The high power density in narrow installation spaces for the $T T$ system is a complex problem remains relevant and requires new solutions, based of case of scientific researches and statistics of operational datasets [4, 8 and 23].

\section{METHODOLOGY OF DIAGNOSTICS THE $T$-BUS MODEL PERFECTION LEVEL}

In designing practice of urban passengers' transport for comparison of models by its technical/technological perfection usually a limited set $\Omega$ of physical informative parameters and characteristics used, which numerical values for each sample contain in available to customers in open access corporate catalogs, for example:

$$
\begin{aligned}
\Omega= & \left(J_{\Sigma}, J_{S}, m_{\Sigma}, N_{\Sigma}, L_{p A}, V_{\max }, V_{a m}, W_{\max }, D_{a m}, R_{t c},\right. \\
& \left.L_{T}, L_{W}, \ldots\right),
\end{aligned}
$$

where $J_{\Sigma}$ - total passengers capacity; $J_{S}$ - seats capacity; $m_{\Sigma}-$ mass of the loaded vehicle; $N_{\Sigma}-$ total installed capacity of the TEM; $L_{p A}$ - noise level in inside; $V_{\max }, V_{a m}$ - maximum speeds of the $T$-bus in contact network mode and in autonomy; 
$W_{\max }$ - maximum acceleration of transport; $R_{t c}-$ the turning circle radius; $D_{a m}$ - distance in autonomy mode; $L_{T}$ - the average lifetime distance of $T B ; L_{W}$ - manufacture' warranty.

According to the international standards, the branch technical regulations and other normative documents for $M_{3}$ category vehicles, the main parameter determining the dimensions of the $T$-bus, its mass, wheel formula, maneuverability and power of TEM, is the total passenger' capacity $J_{\Sigma}$ [31]. It is this characteristic in the conditions of traffic speed limits that is decisive in determining the social effects of the vehicle application - the volume of traffic and environmental friendliness. All parameters that reflect the comfort and ergonomics of human transportation, energy efficiency of the transportation process, resource saving in the manufacture and operation of the vehicle, as well as other characteristics, the total number of which for modern transport reaches $80 \ldots 100$, are subordinated and systematically related to the main parameter $J_{\Sigma}$ [24]. For example, in the frequent start-stop cycle of the $T$ bus operation mode, most of the energy consumed by the TEM is in acceleration cycle part and then dissipated in braking. Two main variables affect this energy: the total mass of the loaded vehicle $m_{\Sigma}$ and its maximum speed value $V_{\max }$.

Reliability of vehicles is convenient to analyze and evaluate as reliability of complex systems consisting of subsystems (body, chassis, electrical, mechanical, pneumatic and hydraulic), units, modules, elements (TEM, M-G, TSC, TB, frequency control unit, speed sensors, $D A$, gears, bearings etc.) $[4,6]$.

At the present stage of intensive updating of vehicle' production the process of statistical dataset formation about reliability of their new systems is limited by the necessity of long period of tests and operation. Therefore, in the majority of corporate catalogs there is no any information on indicators of reliability of vehicle in general and also of its most loaded and responsible subsystems, units, modules etc.

According to the current standards the $T$-bus considered such that it has fulfilled its resource after running 600 thousand $\mathrm{km}$ from the time of commissioning or after a full depreciation period of $10 \ldots 12$ years. Long-term experience in the operation of the $T$-buses shows that the costs of maintaining are several times higher than the initial cost of vehicle. In particular, maintenance and repair of the electromechanical TT is up to $40 \%$ of the $T$-bus' total operating costs. Hence, the problem of ensuring the operational reliability, diagnostics its technical state and predicting its resource is topical [26, 35].

Today, designing process and the organizations of the batch oriented production of urban transport is connected with considerable capital investments, and the full cycle of manufacturing of a new model, including scientific research, development of the project and testing, doesn't exceed 2...3 years. Such short terms are, as a rule, insufficient for accumulation of statistical information about the perfection of vehicles with long life cycle, and wrong assessment leads to substantial damages. Therefore, it is very important correctly estimate the intensity of expected functional and consumer properties at an early stage in the design phase.

There are various approaches to solving this problem, with the following in common:

- Identify a necessary and sufficient set of functional and consumer properties that determine the perfection level of the vehicle' model.

- For each property, an adequate indicator, characterizing its intensity, to prove.

- For each of the alternative projects the numerical values of the benchmark of perfection to established, according to which the analogs compared and the most acceptable one, to accept.

Most of the known methods for diagnostics the perfection level of vehicles, as well as other products of mechanical engineering, based on comparing the aggregate of the quality indicators of the model to evaluate with the corresponding set of indicators for the reference sample and using of expertly established weighting coefficients $[17,21]$.

In accordance with the ISO Recommendations for the reference sample make a really achievable set of values of perfection indicators of objects that require comparison [22].

Must regulated clearly the selection of the comparison base largely determines the result of the evaluation and further decisions hence this process. The basic model should be promising if it takes a lot of time (more than 3 years) to develop new models, providing for the introduction of an amendment to the projected improvement of its key indicators by the time of development and operation. Given the closed nature of any information on prospective samples, as well as the proximity of known methods for diagnostics and forecasting main aspects of quality, the condition of strict regulation of choice of base sample remains unrealized in practice.

More objective on today method of diagnostics the technical/technological level of high-tech engineering products is based on the system hierarchical model in space of $n$ rated dimensionless indicators $0,1<q_{i} \leq 1,0 \forall i=\overline{1 ; n}$ without the use of expertly established weighting coefficients [10]. At the same time, practically unlimited number of indicators $q_{i}$ is determined only by the altitude of the hierarchical model being formed, taking into account the requirements of consumers and production possibilities. The determination of indicators $q_{i}$ values for reference 
samples is based on regression models and corresponding trends over long time intervals.

The ordinary least squares method (OLSM), most common in regression analysis practice, is very sensitive to the number of independent variables and the presence of emissions, which leads in most cases to a decrease in the accuracy of the estimated characteristics and the results of their extrapolation. To improve the accuracy of analysis and extrapolation of results in small samples the modified Kendall-Theil robust method (KTRM) as nonparametric alternative to $O L S M$ define of linear regression equation $\hat{Y}=\hat{b}_{0}+\hat{b}_{1} X$ applied [7].

An iterative process, aimed at finding effective independent variables, used to predict the values of dependent indicators, represents the formation of such models practically tested in the simulation of mechanical systems in gears, railway wheel boxes, aviation simulators etc. $[9,10]$.

\section{OPEN ACCESS DATA COLLECTION}

\subsection{Characteristics and specific indicators of the $T$-bus model perfection level}

Wide choice of $T$-buses available in the world market, only in the period $2010-2016$ proposed 22 models (including 14 ones manufactured in China and Ukraine), that indicates intensive search of ways of increasing of similar models competitiveness not only by the price competition, but mainly by the technical/technological innovations $[2,11,15,30]$.

Relevant problem of applied researches for scientific ensuring the specified processes is definition of steady trends of requirements of consumers to the main physically informative indicators of vehicle perfection and justification of possible ways of their achievement with real technical, technological and economic capabilities of production.

With the use of open access information sources systematized and generalized a set of parameters of serially produced $T$-buses models for a period over 60 years. Also are used some data of the Electric $T$ bus group about deliveries and the order by consumers the most popular models in the period 2000-2019 [29].

From the analysis of evolutionary changes of a lot of parameters and characteristics of perfection for a general sample of the $58 \mathrm{~T}$-bus models established some stable evolution changes in the capacity of passengers $J_{\Sigma}$ and seats $J_{S}$, the total mass (weight) of the vehicle $m_{\Sigma}$, the TEM capacity $N_{\Sigma}$ and normative noise level $L_{p A}$ in inside (table A, Appendix). For the automatic filtration of such information that in many cases has free mode text form the mining log-by-log methods of content examination effectively applied [23].

For a possibility of statistical analysis of the $T$ bus evolution the general sample set in the period
1990-2016 model' year have been differentiated on 5 clusters reflecting indistinct sets of three countries (Canada, China, Ukraine) and two interstate unions $(E U+$ Switzerland) and CIS (Belarus + Russia), defining various distinctions economic, climatic, opportunities for cooperation, national standards etc.

The slope $\hat{b}_{1}$ computed by comparing each data pair to all others in a pair wise fashion. A data set of $l(X, Y)$ pairs will result in $l(l-1) / 2$ pair wise comparisons. For each of these comparisons a slope $\Delta Y / \Delta X$ computed. The nonparametric slope took the median of all possible pairs of slopes.

The intercept $\hat{b}_{0}$ by the following mode defined:

$$
\hat{b}_{0}=Y_{\text {med }}-\hat{b}_{1} X_{\text {med }},
$$

where $X_{\text {med }}$ and $Y_{\text {med }}$ are the medians of $X$ and $Y$ respectively.

These are the advantages of KTRM in contrast to $O L S M$ regression. The KTRM lines dues not depend on the normality of residuals for validity of significance tests and not strongly affected by outliers. The root mean square error (RMSE) is standard deviation of residuals, indicates lack of precision in the population of residuals errors. The smaller is the RMSE of the model, the more accurate the predictions and the better is the model.

Because of consecutive application of the KTRM the trends of some stable in time specific indicators of vehicle' perfection established, namely:

- The relative mass $m_{\Sigma} / N_{\Sigma}$ reflects the system requirements to cost indicators of production and operation of modern vehicles, impact of a complex of factors with opposite gradients, associated with the process of updating the manufactured models, demonstrate a steady downward to minimum $60 \ldots 80 \mathrm{~kg} / \mathrm{kW}$ in articulated body models (fig. 3). Noted, that since 1990 practically all considered models correspond to requirements for vehicles category $M_{3}$ indicator of specific power $N_{\Sigma} / m_{\Sigma} \geq 5,0 \mathrm{~kW} / \mathrm{t}, \quad$ equivalent to $m_{\Sigma} / N_{\Sigma} \leq 200 \mathrm{~kg} / \mathrm{kW}$ [32].

- The relative power of the TEM $N_{\Sigma} / J_{\Sigma}$ reflects main requirements for traction-dynamic characteristics and the vehicle' maneuverability on urban routes tends to steady growth to maximum $3 \ldots 4 \mathrm{~kW} /$ pass in articulated-body models (fig. 4).

- The relative seat' capacity $J_{S} / J_{\Sigma}$ reflects the complex requirements for comfort and safety of traffic tends to steady growth to maximum $45 \ldots 50 \%$ in articulated-body models (fig. 5).

- The relative noise in inside of vehicle $L_{p A} / L_{p R}$ reflects a set of ergonomic requirements related the driver' working conditions, comfort of passengers and the harmful impact on the environment, 
demonstrate a steady downward to minimum $0,15 \ldots 0,3 \mathrm{dBA} / \mathrm{kW}$ in articulated-body models (fig. 6).

The relevance of increasing the profitability of urban transport is completely coordinated with emergence in the market of new $T$-bus articulatedbody models with highest values of the accepted specific indicators.

Most of the $T$-bus' models from general sample the period 1990-2016 (table A) are already quite light (relative curb mass without passengers and cargo is under $100 \mathrm{~kg} /$ pass), but nonetheless still over twice heavy as the aircrafts.

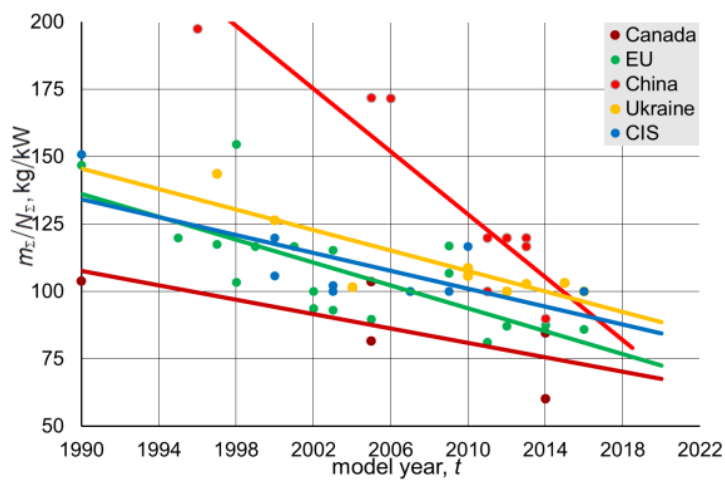

Fig. 3. Trends of indicator $m_{\Sigma} / N_{\Sigma}\left(R^{2}=0.53 \ldots 0.85\right)$

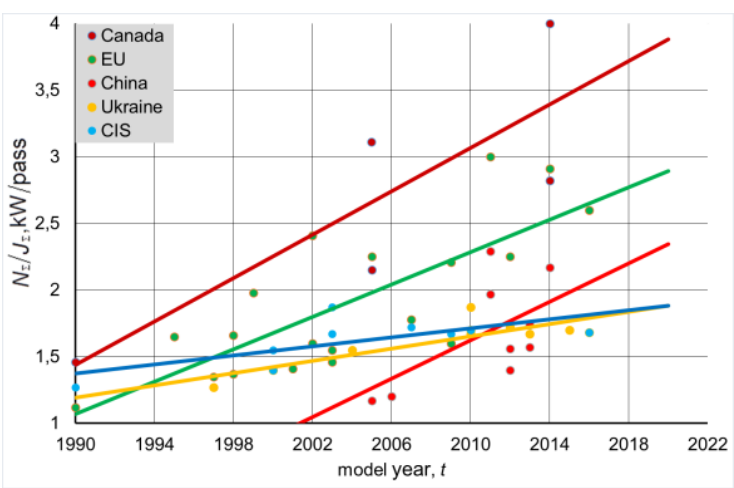

Fig. 4. Trends of indicator $N_{\Sigma} / J_{\Sigma}$ $\left(R^{2}=0.51 \ldots 0.71\right)$

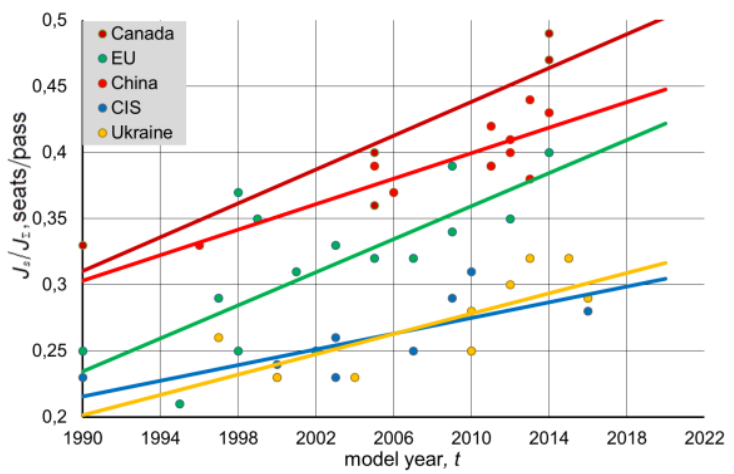

Fig. 5. Trends of indicator $J_{s} / J_{\Sigma}$ $\left(R^{2}=0.51 \ldots 0.83\right)$

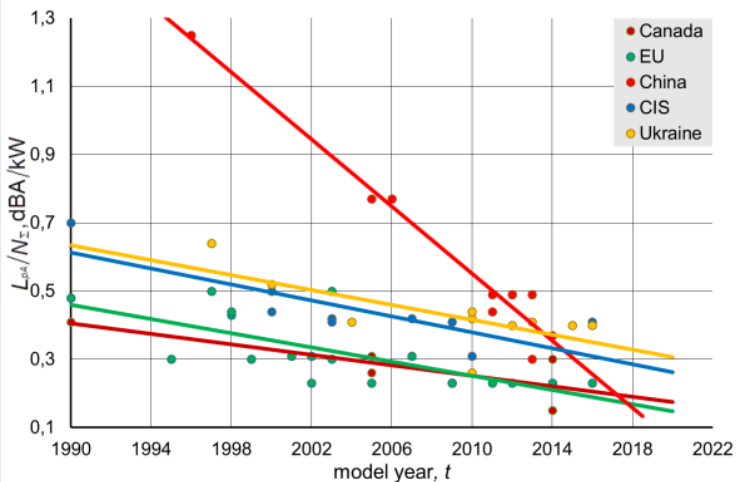

Fig. 6. Trends of indicator $L_{p A} / N_{\Sigma}$ $\left(R^{2}=0.51 \ldots 0.96\right)$

So there is scope for reducing the $T$-bus mass either by using lightweight materials or thinner elements with its optimum design and manufacturing. On the example of comparison the two $E$-drive models of pick-up track (basic on GREET 1 and lightweight on GREET 2) the possibility of decrease in mass the test vehicle up to $26 \%$ confirmed [3].

Design recommendations on some effective constructive/technology solutions namely are given:

- Replacement of steel elements of the pick-up track' body by carbon fiber composite provides decrease in mass up to $52 \%$.

- Replacement of the TB Ni-MH or Li-ion (with the chemical composition of 2006 model year) on ones with more modern models provides decrease in their mass up to $30 \%$.

- Replacement of steel DA on ones of cast $\mathrm{Al}$ provides decrease in their mass up to $47 \%$.

Air resistance is not a significant energy consumer in urban traffic, but nonetheless in seeking to minimize energy use better dynamic shape should not be overlooked in designing new $T$ bus models.

Established trends of all specific indicators also specify the TT loads increasing, indicate the need for new conditions the regulatory indices of transferred power, mass, vibration resistance, durability, availability, operational reliability etc.

As a guide the $T T$ energy efficiency can be improved by reducing the number of friction interfaces in the drive chain and mainly by use of gears with the internal gearing characterized by the highest value of mechanical effectiveness index $\eta$. Using of the compact multi-threaded gears (MTG) makes it possible to reduce the main gear' and semi-axle' dimensions and mass of up to $25 . . .50 \%$ [19].

\subsection{Diagnostics of $\boldsymbol{T}$-bus model' perfection level}

According to the methodology of quality measurement, the index of perfection level of the evaluation object usually displays several dissimilar service properties of the object, close in importance [4, 8, 10, 24 and 36]. 
In many cases $n$ indicators of the object' properties $q_{i} \forall i=\overline{1 ; n}$ are interrelated, that's, they are united by a certain functional dependence. If such dependence theoretically or empirically can be established, then the perfection level estimated by dimensionless index $\gamma=f\left(q_{i}\right) \forall i=\overline{1 ; n}$.

Such index for the $T$-bus, which decides whether to produce or purchase a certain model, should be a complex indicator combining the main parameter $J_{S}$, as well as the necessary and sufficient set of indicators, that takes into account the basic physically informative parameters of vehicle perfection (1). The gradients of temporary trends of such indicators can be identical or opposite according to the sign (fig. $3-6$ ).

The relationship between a function defined through dimensional indicators can based on the similarity theory and the well-known $\pi$-theorem in the following formulation:

"Any constant physical relationship between dimensional quantities can be formalized as a ratio of dimensionless quantities".

When solving problems using the dimensional analysis method, a complete absolute or completeness, depending on the number of variable task parameters and the number of established basic units of measurement obtained. For example, if the desired function depends on 4 variables with 3 basic units of measurement (mass $M$, length $L$, time $T)$, then the problem of determining such function has a complete solution up to a certain value of the constant coefficient $k=$ const $[27,33]$.

The desired function taken in the form of product of three independent variable arguments, each of which has an unknown exponent, that's,

$$
\gamma=k\left(N_{\Sigma}\right)^{a} \cdot\left(m_{\Sigma}\right)^{b} \cdot\left(V_{\max }\right)^{c} .
$$

Matching dimension formula for equation's (1) both parts with the basic units $M, L, T$, as a result of identical transformations of the power dimension $\left[\frac{\mathrm{N} \cdot \mathrm{m}}{\mathrm{s}}=\frac{\mathrm{kg} \cdot \mathrm{m}^{2}}{\mathrm{~s}^{3}}\right]$, and acceptable for problems with the physical nature of the relationships between the variable arguments by the value of the coefficient $k=g^{-1} \quad\left(g=9.8 \mathrm{~m} / \mathrm{s}^{2}-\right.$ the acceleration of gravity), has such form:

$$
\frac{L}{T^{2}}=\left(\frac{M \cdot L^{2}}{T^{3}}\right)^{a} \cdot M^{b} \cdot\left(\frac{L}{T}\right)^{c}
$$

It follows from formula (3) that all three variables are expressed in terms of three basic measurement units therefore the task posed has not only a complete but also an absolute solution. According to the identity condition for each dimension with its grade on the left and right sides of the equation (4) for the exponents for $L, T, M$, the system of equations $2 a+c=1 ; 3 a+c=2 ; a+b=0$ and it solution $a=1 ; b=-1 ; c=-1$ obtained.
The index of perfection of the valuation objects should reflect the necessary and sufficient number of parameters and characteristics, which significantly affect certain trends in their evolution (fig. 3-6).

If to accept the index $\gamma$ (3) as the criterion of functional similarity the serially made $T$-buses, then the necessary and sufficient number $n$ of dimensionless indicators $q_{i} \forall i=\overline{1 ; n} ; 0,1<q_{i} \leq 1,0$ is provided. Each of indicators displays a certain property of the vehicle' model and allows some periodic updating in accordance with priority requirements of consumers, designers or manufactures.

Taking into account, for example, three specific indicators $J_{S} / J_{\Sigma}, L_{p R} / L_{p A}, P_{S T} / P_{S R}$, a kernel of model (3) supplementing, the hypothesis of their paired independence on preference by consumer, designer and manufacturer, an expression for the index $\gamma$ as a function of 9 variable arguments obtained

$$
\gamma=\frac{N_{\Sigma} \cdot 10^{3}}{m_{\Sigma} V_{\text {max }} g}\left(\frac{J_{S}}{J_{\Sigma}}\right) \cdot\left(\frac{L_{p R}}{L_{p A}}\right) \cdot\left(\frac{P_{S T}}{P_{S R}}\right),
$$

where $L_{p R} / L_{p A}, P_{S T} / P_{S R}$ - the noise level in for the reference sample relatively certain $T$-bus' model; $P_{S T} / P_{S R}-$ defined level of reliability for the certain model relatively reference sample.

For the preliminary analysis of the available dataset accepted values $L_{p R}=72 \mathrm{dBA}$ (for today the lowest noise level among the available general selection), indicator of system reliability $P_{S T} / P_{S R}=$ const $=1,0$, i.e., the number of variable arguments $n=7$ of the index function $\gamma^{\prime}=f\left(q_{i}\right)$, assumed as the first approach.

From the analysis of the trends follows that for today the highest values of the index $\gamma^{\prime}$ by models from Canada, $E U$ and China are determined (fig. 7).

The following stage of development the offered model (5) is connected into accounts the features of modern $T$-buses models by formation the sufficient electrical, electronic, mechanical and other systems and subsystems (inverters, the TEM, TT, TB, TSC, etc).

The technique of definition the next approximation of index $\gamma$ taking into account the structural reliability of the $T T$ system is considered.

\subsection{Evolutionary changes in $\boldsymbol{T T}$ system}

The specified set of low floor models and certain trends in power, mass, comfort and ergonomics indicators led to a number of evolutionary changes in the structure and design of the TT system, which are conveniently combined and classified as follows (table 2):

- Module of drive' axle (DA), used in the $T$-buses from about 1958 model year (hereinafter $D A$ the $1^{\text {st }}$ generation), has a structure borrowed from 
buses and trucks (the beam, the cardan shaft, two semi-axles, main gearing, mechanical differential $(M D)$, two single-stage spur planetary wheel gears $-P W G$ ) (fig. 8, a).

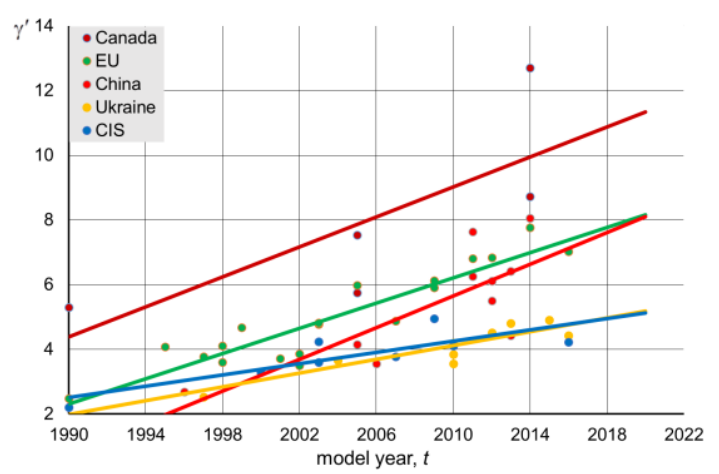

Fig. 7. Trends of the index $\gamma$ in the first approach $-\gamma^{\prime}\left(R^{2}=0.59 \ldots 0.85\right)$

- Since 1995 the $D A$ received a lower beam, inline helical gear $(I H G$ instead of $P W G)$ and the corresponding name - portal drive axle (hereinafter $D A$ the $2^{\text {nd }}$ generation). Purpose for the $T T$ with a group drive from the TEM through the cardan shaft, conical transmission with a circular tooth, the inter axle conical $M D$, the semi-axles connected with the $I H G$ (twostage helical cylindrical gear with branching, the slow gear is directly connected to the drive wheels (fig. 8, b).

- In 2007-2016 designing, tests and development of serially production of the electric portal $D A$ based on motor-wheels with aggregated asynchronous TEM with water/glycol cooling, the $I H G$ and the $P W G$ without the cardan shaft, the semi-axles, final drive and $M D$ (hereinafter $D A$ the $3^{\text {rd }}$ generation), are successfully complete. Purpose - for electromechanical transmissions with individual drive for each drive wheel (aggregated motor-wheels - AM$W$ ), in which the TEM are connected with the two-stage $I H G$ and a single-stage $P W G$ (transmissions of cylindrical, helical, fixed rings are located in the hubs of the $A M-W$ and the carrier is connected with a drive wheel, fig. 9).

- In 2014 the production of portal DA based on wheel-hub drive (integrated motor-wheels IM$W$ ) with synchronous TEM on permanent magnets with water/glycol cooling and disk brake with hydraulic drive, the beam includes two $I M-W$ (hereinafter $D A$ the $4^{\text {th }}$ generation, fig. 10). Purpose - for electrical $T T$ with an individual drive in particular in $E$-buses for shuttle-service.

Therefore, the electromechanical $T T$ of modern $T$ - and $E$-buses with a group or individual drive scheme can consist of the TEM of direct or alternating current, universal joints, as well as one or two DA with non-lowered or portal (lowered) beam. In transmissions with a group drive scheme, the $D A$ module can consist of a main transmission of a conical/hypoid type, a conical differential, semi-axles the same or different lengths and split gears.

For the $D A$ the $1^{\text {st }}$ generation with non-lowered beam, the central location of the main gear and the inter-axle mechanical differential with the axle shafts having the same length, which ensures the symmetry of the dynamic load of the transmission along the sides of the $T$-bus, are characteristic. All this placed in the hull, forms a beam of the $D A$ (fig. 8 , a). The use of compact multi-threaded gears $(M T G)$ makes it possible to reduce the dimensions and mass of the main gear and semi-axles by 1.5...2.0 times. The $D A$ half-axles have different lengths, which makes possible take the cardan shaft away from the middle of the passenger compartment, place the TEM on the rear cantilever part of the $T$-bus body closely to the $D A$, allows for partial lowering of the cabin's floor, simultaneously simplifies the TT design and improves its reliability (fig. 8, b).

Modules of the $D A$ the $1^{\text {st }}$ and $2^{\text {nd }}$ generations contain gears with a total gear ratio $u=5.11 \ldots 10.67$, which is realized by the central hypoid $(u=3.09)$ or conic $(u=2.72)$ transmissions and planetary wheel or $I H G(u=3.46 \ldots 3.55)$. Due to the insufficient balance between torque, mass and volume of TEM for each $A M-W$ in the $D A$ the $3^{\text {rd }}$ generation the multi-stage gear boxes (IHG and $P W G$ ) provide a transmission ratio of the $T T$ at the level of $20 . .23$, maximum torque $22 \times 485 \mathrm{Nm}$ and the necessary compactness of the whole structure.

Differential kinematics connection between the pair of driving wheels of each electric $D A$ and traction force distribution between the two electric $D A$ is provided by the active torque vectoring system (ATVS) - the single system of torque vectoring and braking forces control [15].

The full electric $T T$ structure based on the $D A$ the $4^{\text {th }}$ generation with $I M-W$ (fig. 9) not require the cardan shaft, semi-axles and multistage gears. The $I M-W$ design can be used in two options - like a rotary or non-rotating motor-wheel, the corresponding wheels can be single-track (equipped with wide tires) or dual-track. Modules of the $D A$ the $4^{\text {th }}$ generation compared to the $D A$ the $3^{\text {rd }}$ generation provides the following advantages:

- Increased energy efficiency due to higher in $5 . .7 \%$ value of mechanical effectiveness and the possibility of energy recovery for charging the batteries during electro-dynamic braking.

- Greater vibration resistance and a lower mass of the $D A$ in general. For the known serial models of the $D A 4^{\text {th }}$ generation the nominal noise level is set $65 \mathrm{dBA}$.

So far the lack of data about the reliability of the $D A$ the $4^{\text {th }}$ generation, its limited load capacity, regulatory resource and known high electric danger at service limited their widespread use in $E$-drive vehicles. 
Table 2. Classification features of the $T T$ systems in the $T$ - and $E$-buses

\begin{tabular}{|c|c|c|c|c|}
\hline \multirow{2}{*}{$\begin{array}{l}\text { Features, } \\
\text { examples }\end{array}$} & \multicolumn{4}{|c|}{ Floor level of vehicle } \\
\hline & $\begin{array}{c}\text { not lowered } \\
(>480 \mathrm{~mm})\end{array}$ & \multicolumn{3}{|c|}{ lowered $(320 \ldots 350 \mathrm{~mm})$} \\
\hline 1. The motion energy & & \multicolumn{2}{|c|}{ electromechanical } & electrical \\
\hline $\begin{array}{l}\text { 2. Drive scheme, } \\
\text { kinematics connection, } \\
\text { wheel formula }\end{array}$ & $\begin{array}{c}\text { group, } \\
\text { differential, } \\
4 \times 2,6 \times 2,6 \times 4\end{array}$ & $\begin{array}{c}\text { group, differential, } \\
4 \times 2,6 \times 2,6 \times 4, \\
8 \times 4\end{array}$ & $\begin{array}{c}\text { individual, } \\
E C S, \\
4 \times 2,6 \times 2,6 \times 4\end{array}$ & $\begin{array}{l}\text { individual, } \\
E C S, \\
4 \times 2 ; 6 \times 2\end{array}$ \\
\hline $\begin{array}{l}\text { 3. } T T \text { constituents } \\
\text { (engines, modules, parts) }\end{array}$ & $\begin{array}{c}\text { TEM, } \\
\text { cardan shaft, } \\
\text { module of } D A \\
\text { with not } \\
\text { lowered beam }\end{array}$ & $\begin{array}{c}T E M, \\
\text { cardan shaft, } \\
\text { module of } D A \\
\text { with not } \\
\text { lowered beam }\end{array}$ & $\begin{array}{c}A M-W, \\
\text { module of } D A \\
\text { with lower beam }\end{array}$ & $\begin{array}{c}I M-W, \\
\text { module of } D A \\
\text { with lower beam }\end{array}$ \\
\hline 4. TEM type and design & $\begin{array}{l}\text { permanent } \\
\text { current }\end{array}$ & $\begin{array}{c}\text { permanent } \\
\text { or } \\
\text { alternating current }\end{array}$ & $\begin{array}{c}\text { asynchronous 3-phase, } \\
\text { water-cooled, } \\
\text { aggregated with gears }\end{array}$ & $\begin{array}{c}\text { synchronous } \\
\text { on permanent } \\
\text { magnets, } \\
\text { wheel-hub drive } \\
\end{array}$ \\
\hline $\begin{array}{l}\text { 5. Type of differential } \\
\text { kinematics connection }\end{array}$ & $\begin{array}{c}\text { mechanical, } \\
\text { electromechanical }\end{array}$ & $\begin{array}{c}\text { mechanical, } \\
\text { electromechanical }\end{array}$ & electric & electric \\
\hline $\begin{array}{l}\text { 6. Presence and location } \\
\text { of the main gear and } \\
\text { mechanical differential }\end{array}$ & central & offset & - & - \\
\hline $\begin{array}{l}\text { 7. Presence and types } \\
\text { of split gears }\end{array}$ & $\begin{array}{c}\text { single-stage spur } \\
P W G \\
\end{array}$ & $\begin{array}{c}P W G \text { or } \\
\text { two-stage } I H G\end{array}$ & $\begin{array}{c}P W G \text { and } \\
\text { two-stage } I H G\end{array}$ & - \\
\hline 8. Examples of schemes & Fig. 8, a & Fig. 8, b & Fig. 9 & Fig. 10 \\
\hline
\end{tabular}

\subsection{Circuit-logical model of the $T T$ reliability}

At absence in open access any information on indicators of the TT system's reliability for a preliminary comparison its structures at design the probabilities of fail-less operation of all the elements assumed to be the same, i.e. $P_{j}=0,95(j=1, \ldots, l)$. In the structures with two independent $D A$ assumed, that constant reservation ensure transport operating at reduced speed. If the " $a$ " part of the elements not duplicated in the TT system, and other the " $b$ " part duplicated, the probability of failure-free operation determined by such formulas:

$$
P_{S T}=P_{a} \cdot P_{b} ; \quad P_{a}=\prod_{j=1}^{a} P_{j} ; \quad P_{b}=\prod_{j=1}^{b}\left(1-Q_{j}^{2}\right),
$$

where $Q_{j}$ - the probability of the $j$ element failure.

The calculations results allow roughly compare the known $T T$ structures according to the operational reliability indicator and consider it when determining the index $\gamma$ (table 3).

Taking into account the values of indicator $P_{S T} / P_{S R}$, which reflects the reliability of the $T T$ system, the number of variable arguments of function (5) increased. The highest value of the system indicator of fail-safe operation $P_{S E}=0,931$ distinguish full electric $T T$ with a wheel formula $4 \times 4$ thanks to fewer sources of failure and structural reservation by two $D A$ the $4^{\text {th }}$ generation. This structure allows the vehicle to continue at a lower speed when one of the $D A$ fails.

As a reference sample of comparison los electromechanical $T T$ with the wheel formula $6 \times 4$, $8 \times 4$ based on the $D A$ the $1^{\text {st }}$, the $2^{\text {nd }}$ and the $3^{\text {rd }}$ generation and characterized by the highest among the known analogs indicator' value $P_{S R}=0,883$ (table 3 ) is adopted. The smallest values
( $P_{S E}=0,735 \ldots 0,773$ ) to the $T T$ with wheel formula $4 \times 2$ or $6 \times 2$ based on $D A$ the $3^{\text {rd }}$ generation without structural reservation corresponds.

The second approach $\gamma^{\prime \prime}$ of the index $\gamma$ and corresponding regression lines (fig. 11) confirms significance effect of the certain $T T$ structure reliability on the $T$-bus' perfection level. In particular, compared $\gamma^{\prime \prime}$ with the first approach $\gamma^{\prime}$ (fig. 7) there is a certain excess of the EU models from China's analogs.

Analysis of the circuit-logical models of the TT system function' reliability showed that when designing the following solutions used:

- Structured redundancy by introducing additional elements that ensure the preservation of the system's operability when one or several elements turned on in parallel failed.

- Parametric redundancy ensuring the preservation of the operability of the system or its elements by facilitating operating modes, reducing operating loads and stresses by assigning surplus stocks by criteria of strength, rigidity, vibration resistance, durability etc.

- Structured and parametric redundancy by reducing the number of failure sources at the same time.

Objective functional effectiveness of the known designs of $P W G$ and existence of reserves for further perfecting of electromechanical $T T$ design on the system indexes of reliability, taking into account posterior statistics of service data, historical maintenance records, which contain information about failures and performed repairs is confirmed [1, $6,8,18,23,34$ and 35]. 

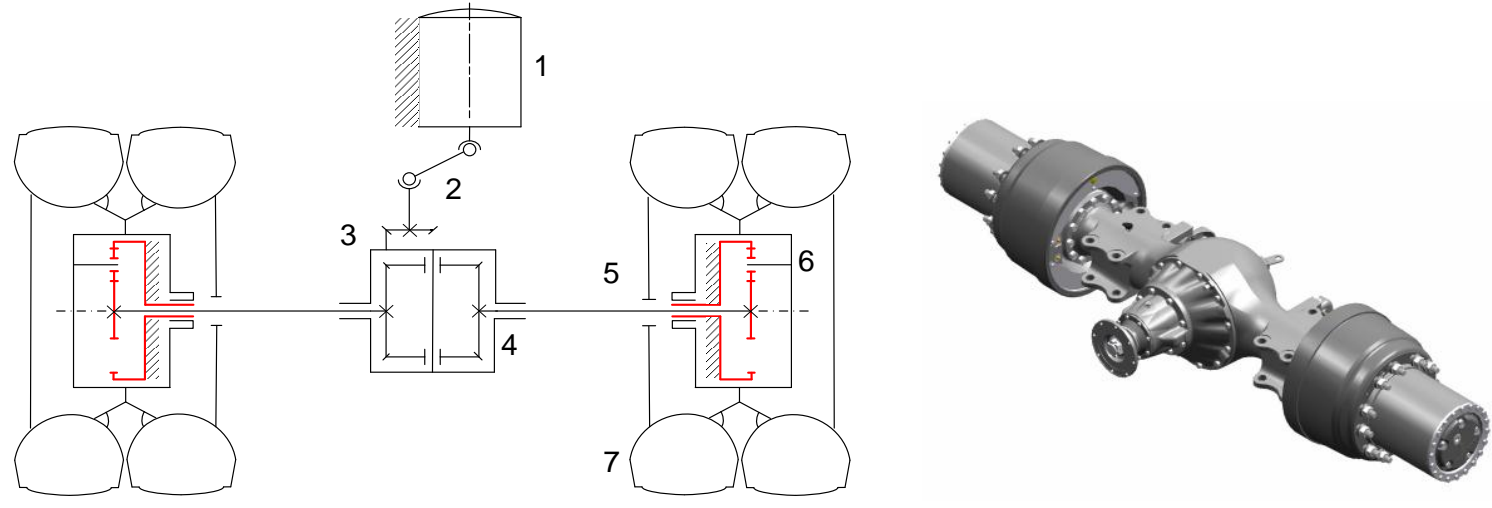

a
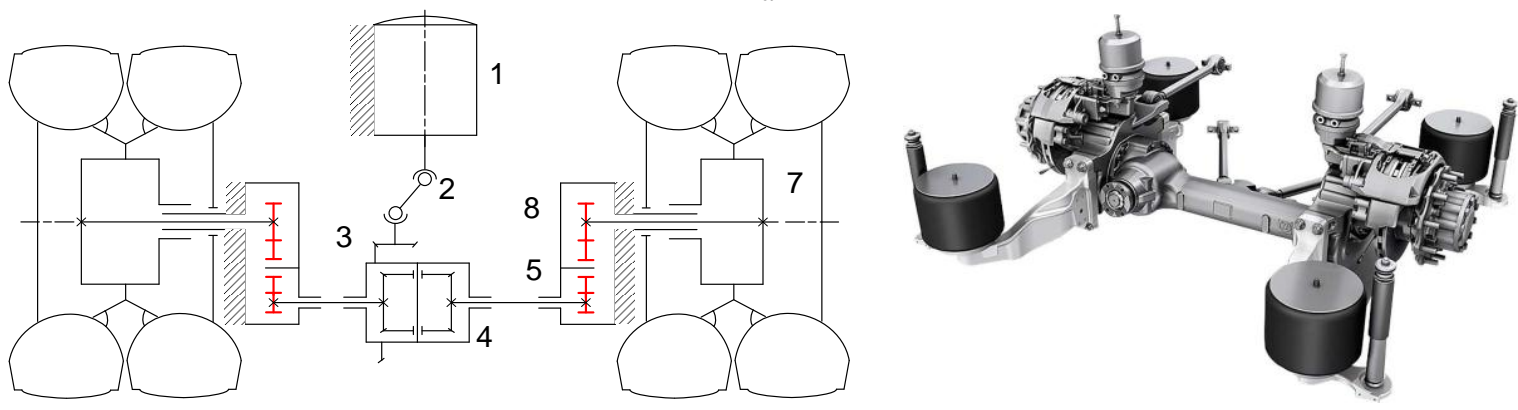

b

Fig. 8. $T T$ schemes and examples of $D A$ the $1^{\text {st }}$ (a) and the $2^{\text {nd }}$ (b) generations, produced by firms Raba, Hungary (types $118.77,318.78$ ) [12] and $Z F$, Germany (type $A V$-133) [14]: 1 - TEM; 2 - cardan shaft; 3 - main gear; $4-M D ; 5$ - semi-axle; 6 - PWG; 7 - driving wheel; 8 - IHG

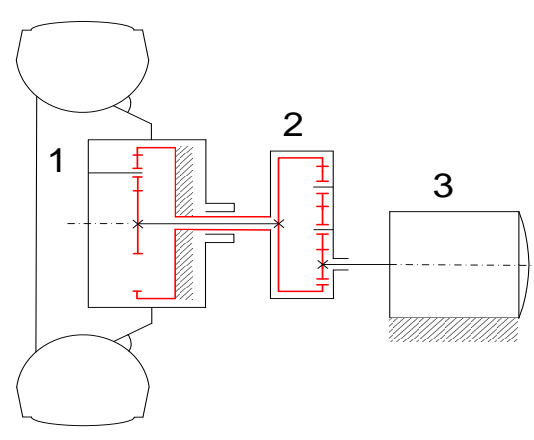

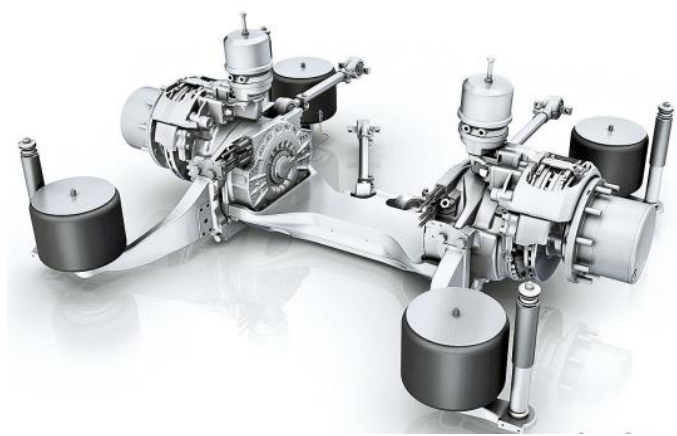

b

Fig. 9. $T T$ scheme of the $A M-W$ (a) and example of $D A$ the $3^{\text {rd }}$ generation (b), produced by firm $Z F$, Germany (type $A V E-130)$ [14]: $1-P W G ; 2-I H G ; 3-T E M ; 4$ - driving wheel

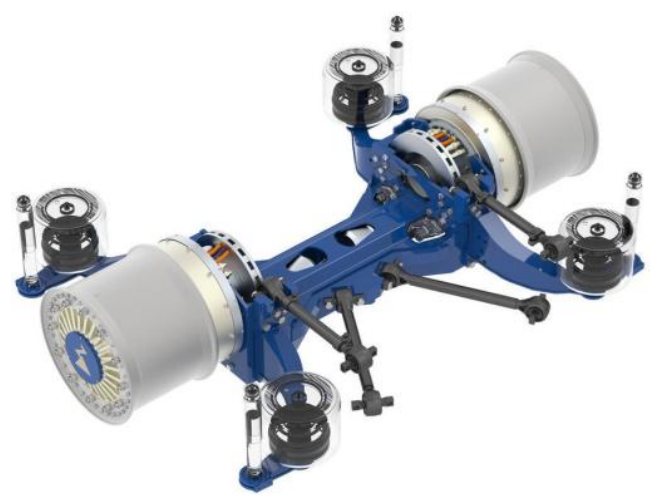

Fig. 10. Example of $D A$ the $4^{\text {th }}$ generation, produced by firm ZIEHL-ABEGG, Germany (type ZAwheel SM 530) [13] 


\begin{tabular}{|c|c|c|c|}
\hline $\begin{array}{l}\text { Wheel formula, } \\
\text { the } D A \text { generation }\end{array}$ & Block-diagram of the $T T$ structure & Calculation formulas & $P_{S T}$ \\
\hline $\begin{array}{l}4 \times 2,6 \times 2, \\
\text { the } 1^{\text {st }} \text { or the } 2^{\text {nd }}\end{array}$ & 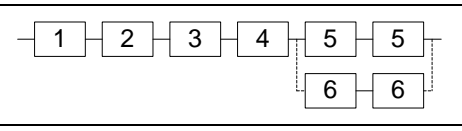 & $\begin{array}{l}P_{S T}=P_{1} \cdot P_{2} \cdot P_{3} \cdot P_{4} \cdot P_{5}^{2} \\
P_{S T}=P_{1} \cdot P_{2} \cdot P_{3} \cdot P_{4} \cdot P_{6}^{2}\end{array}$ & 0.735 \\
\hline $\begin{array}{l}\quad 6 \times 4,8 \times 4, \\
\text { the } 1^{\text {st }} \text { or the } 2^{\text {nd }}\end{array}$ & 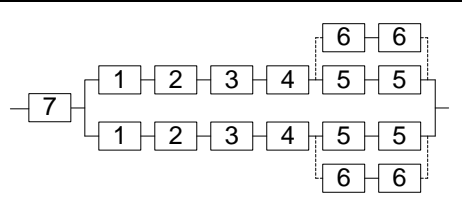 & $\begin{array}{l}P_{S T}=P_{7} \cdot\left[1-\left(1-P_{1} \cdot P_{2} \cdot P_{3} \cdot P_{4} \cdot P_{5}^{2}\right)^{2}\right] \\
P_{S T}=P_{7} \cdot\left[1-\left(1-P_{1} \cdot P_{2} \cdot P_{3} \cdot P_{4} \cdot P_{6}^{2}\right)^{2}\right]\end{array}$ & 0.883 \\
\hline $\begin{array}{l}4 \times 2,6 \times 2, \\
\text { the } 3^{\text {rd }}\end{array}$ & $-8-1$ & $P_{S T}=P_{8} \cdot P_{1}^{2} \cdot P_{9}^{2}$ & 0.773 \\
\hline $\begin{array}{l}6 \times 4 \text {, } \\
\text { the } 3^{\text {rd }}\end{array}$ & 8 - $\begin{array}{l}1-1-5-5-6-6 \\
1-1-5-5-6-6\end{array}$ & $P_{S T}=P_{8} \cdot\left[1-\left(1-P_{1}^{2} \cdot P_{5}^{2} \cdot P_{6}^{2}\right)^{2}\right]$ & 0.883 \\
\hline $\begin{array}{l}\times 2, \\
\text { the } 4^{\text {th }} \\
\end{array}$ & $8-10-10$ & $P_{S T}=P_{8} \cdot P_{10}^{2}$ & 0.857 \\
\hline $\begin{array}{l}4 \times 4, \\
\text { the } 4^{\text {th }}\end{array}$ & $-8-10$ & $P_{S T}=P_{8} \cdot\left[1-\left(1-P_{10}^{2}\right)^{2}\right]$ & 0.94 \\
\hline \multicolumn{4}{|c|}{$\begin{array}{l}\text { Note. The following designations are accepted: } 1-T E M ; 2-\text { cardan shaft; } 3-\text { main gear; } 4-M D ; 5-P W G ; 6-I H G \text {; } \\
7-E M D ; 8-A T V S ; 9-A M-W ; 10-I M-W .\end{array}$} \\
\hline
\end{tabular}

The main features of electromechanical $T T$ structures designing for given conditions of arrangement and interface of all components in restricted space, also preferred application of the reference, unified details and modules, leads that many elements of system have the dimensions exceeding durability, necessary by criteria of strength, rigidity, stability of oscillations, i.e. are obviously reliable.

At the same time on design there are details and modules, which dimensions owing to external restrictions cannot increase. Examples of such "weak" elements of the $T T$ systems based on the $P W G$ and $I M-W$ modules the thin walled epicycles and satellite' pinion bearings are [8, 16 and 34]. According to established trends of indicator $N_{\Sigma} / J_{\Sigma}$ (fig. 4) the operating loads on low-speed tooth gearings during 2010-2016 in 35...40\% increased, that causes the need of modernization of the known designs taking into account stochastic and alternating nature of heavy mode loads and elastic fluctuations in the $T$-bus' electromechanical $T T$ structures.

High power density in narrow installation spaces in special requirements for leading away power losses resulting. As a rule such elements in reliability theory, known as "weak links" or "criteria elements", the all system reliability limited.

Most efficient ways of parametrical redundancy the $T$-buses $T T$ systems based on the $D A$ the $1^{\text {st }}$, the $2^{\text {nd }}$ and the $3^{\text {rd }}$ generations are:

- Watching diagnostics as a function of technical systems reliability and protection of gear transmissions from harmful effects - shock loads, vibrations, the parametric resonance phenomena in non-stationary operation mode [8, 16 and 34].

- Application the hierarchical model based on $n$ rated dimensionless indicators of perfection for the $C A E$-design of multi-stages $P W G$ and $I H G$ with internal spur or bevel gears, each of which provides the overlap factor of more than 3,0 [10].

- Development of roller bearings designs with increased load capacity and minimum friction losses for its application in high-loaded $P W G$ and $I H G$ with narrow installation space [9].

-

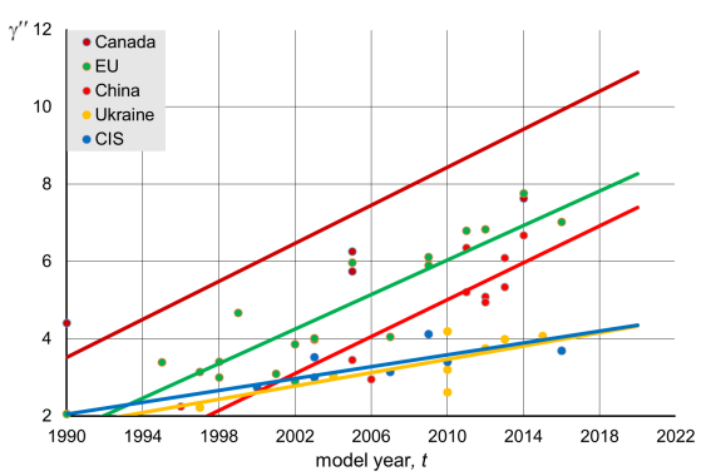

Fig. 11. Trends of the index $\gamma$ in the second approach $-\gamma^{\prime \prime}\left(R^{2}=0.57 \ldots 0.82\right)$

\section{CONCLUSION}

Today the process of designing and organizing the serial production of urban passenger transport is associated with significant capital expenditures, and the full cycle of manufacturing a new model, including scientific research, design development and testing, reaches three and more years. Therefore, it is very important correctly estimate the intensity of expected functional and consumer properties at the early stages of vehicle' design, that has consequently an impact to the decision-making.

In this work the main trends of the $T$-bus and its main loaded systems and modules - the $T T$ and $D A$, 
evolution trends established and in number reflected. As a result of the executed research existence of demand in the world market and objective technical reserves for updating and expansion of the $T$-bus' technology is confirmed.

The open access dataset for further development directly by designers and customers in order to precision and extrapolation accordingly with the $T$ and $E$-buses evolution trends presented.

The technique of taking note of the $T T$ system aprioristic reliability at express diagnostics of certain vehicle' model perfection level developed.

The relevance of scientific research, development of innovative technologies for $T$ - bus' designing and serially production, for which the advancing values of perfection level index wellfounded theoretically and confirmed statistically, accented.

Accented also, that open access to objective dataset of the vehicle' models perfection' indicators is one of the foremost challenges in methodology of the $C A E$-methods machine optimal design and have practical significance to improve the accuracy of the decisions, which influence on the reliability' diagnostics, safety and maintenance costs on this basis made [5].

The relevance of offered models, methods and techniques, datasets and perfection' indicators evolution trends for consumers, designers and manufacturers from Ukraine and Belarus is due not only to renew the fleet of urban passenger transport, but also to establish relations of scientific and technological multilateral mutually beneficial cooperation, to search for suppliers of components for own production the new models to EU market oriented and the world technical/technological level corresponded.

The offered results and recommendations do not apply for completeness of coverage of all the factors influencing the rates of evolutionary development and updating of the urban transport in various countries, often incomparable on their economic potential, tactical and strategic priorities. However, there is also a considerable amount of uncertainly in the market share of the $E$-drive urban transport that must be taken into account in further researches.

\section{REFERENCES}

1. Ariza JM, Gutyria SS, Jomyak YM. Tensiones en ejes huecos con una grieta superficial bajo flexión rotativa. Revista DYNA. 2014; 89(1): 85-88. https://doi.org/10.6036/5822

2. Baguette, St. Solaris Electric \& Fuel Cell Buses. Members Seminar, Brussels; 2016.

3. Burnham E. Updated Vehicle Specifications in the GREET Vehicle-Cycle Model. Center for Transportation Research. Argonne National Laboratory. USA; 2012.

4. Chunhui G, Chuan L, Jiayu C. Zhou D. Design approach based on a correlative relationship between maintainability and functional construction. Maintenance and Reliability. 2018; 20(1): 115-124. http://dx.doi.org/10.17531/ein.2018.1.15

5. Eysenbach G. Citation advantage of open access articles. PLoS Biol. 2006; 4(5), e157: 0692-0698. https://doi.org/10.1371/journal.pbio.0040157

6. Feki N, Clerc G, Velex Ph. Gear and motor fault modeling and detection based on motor current analysis. Electric Power Systems Research. 2013; 95: 28-37. https://doi.org/10.1016/j.epsr.2012.08.002

7. Granato, G.E. Kendall-Theil Robust Line (KTR Lineversion 1.0). A visual basic program for calculating and graphing robust nonparametric estimates of linearregression coefficients between two continuous variables. In: Techniques and Methods of the U.S. Geological Survey, book 4, chap. A7; 2006:1-31.

8. Gutyria S, Bordeniuk D. Diagnostics of damages in trolleybuses wheel reduction gears. Motrol 2008; T. 10a: 65-71.

9. 9.Gutyria SS, Yaglinskyi VP, Gaydamaka AV. Technical level of rolling bearing. British Journal of Applied Science \& Technology 2016; 13(2): 1-9. https://doi.org/10.9734/BJAST/2016/20747

10. Gutyria S, Zablonsky K, Yaglinsky V. System modeling of gears design quality. VDI-Berichte 2005; 1904.1: 417-434. Matched ISSN: 0083-5560

11. Hamacek S, Bartłomiejczyk M, Hrbác R, Misak S. Styskala V. Energy recovery effectiveness in trolleybus transport. Electric Power Systems Research 2014; 112: 1-11.

https://doi.org/10.1016/j.epsr.2014.03.001

12. http://www.raba.hu/axle/bus_and_trolleybus_axles.ht $\mathrm{ml}$

13. https://www.zf.com/site/magazine/en/articles_10624.h $\underline{\mathrm{tml}}$

14. https://www.zf.com/products/en/buses/products_2919 8.html

15. Jalali K, Uchida T, Lambert S. McPhee J. Development of an advanced torque vectoring control syste $\mathrm{m}$ for an electric vehicle in-wheel motors using soft computing techniques. SAE Int. J. Alt. Power 2013;2(2): 261-278. https://doi.org/10.4271/2013-010698

16. Li JY, Hu QC, Zong CF, Zhu TJ, Zhang ZX. Vibration characteristics of two-stage planetary transmission system with thin-walled ring gear on elastic supports. ICMES 2017. IOP Conf. Series: Materials Science and Engineering. 2018; 339: 1-7. https://doi.org/10.1088/1757-899X/339/1/012010

17. Kalemba N, Campa-Planas F. The quality profitability link in the us airline business: a study based on the airline quality rating index. Procedia Engineering. 2017; 187: 308-316. https://doi.org/10.1016/j.proeng.2017.04.380

18. Kepka M, Kepka M. Parametric calculations of fatigue life of critical part of trolleybus rear axle. Procedia Engineering 2018; 213: 227-238. https://doi.org/10.1016/j.proeng.2018.02.024

19. Khan DI, Virtanen S, Verma AK. Automotive transmission system design based on reliability parameters. Journal of Reliability \& Statistical Studies 2012; 5(2): 59-76. https://www.jrss.in.net/assets/5206.pdf

20. De Decker, K. Get wired (again): Trolley-buses and Trolley-trucks. Lowtechmagazine 2009.

21. Li ZJ, Chen XL, Ding M. Energy Consumption and Pollutant Emissions. Comparison between Electric and Non-electric Vehicles: Modeling Approach. Procedia Environmental Sciences 2012; 13: 550-554. https://doi.org/10.1016/j.proenv.2012.01.045 
22. Marjanen, Yka. Validation and improvement of the ISO 2631-1 (1997) standard method for evaluating discomfort from whole-body vibration in a multi-axis environment. Loughborough University; 2010.

23. Marzec M, Uhl T, Michalak D. Verification of text mining techniques accuracy when dealing with urban bases maintenance data. Diagnostyka 2014; 15(3): 5157.

24. Meidute-Kavaliauskiene I, Stanujkic D, Vailiauskas AD, Vasilienè-Vasiliauskienè V. Significance of Criteria and Resulting Significance of Factors Affecting Quality of Services Provided by Lithuanian Road Freight Carriers. Procedia Engineering 2017; 187: 513-519.

http://dx.doi.org/10.1016/j.proeng.2017.04.408

25. Moro A, Lonza L. Electricity carbon intensity in European Member States: Impacts on GHG emissions of electric vehicles. Transportation Research 2018; Part D 64: 5-14. https://doi.org/10.1016/j.trd.2017.07.012

26. Qiu ZP, Huang R, Wang XJ, Qi WC. Structural reliability analysis and reliability-based design optimization. Recent advances. Sci. China - Phys. Mech. Astron. 2013; 56: 1611-1618.

https://doi.org/10.1007/s11433-013-5179-1

27. Shen W, Davis T, Lin KJ. Nachtsheim CJ. Dimensional analys and its applications in statistics. Journal of Quality Technology 2013: 1-19. https://doi.org/10.1080/00224065.2014.11917964

28. Slavík J. Electric Buses in Urban Transport. The Situation and Development Trends. Journal of Traffic \& Transportation Engineering 2014; USA, 1(2): 4558. https://doi.org/10.17265/2328-2142/2014.06.005

29. The Electric $T$-bus group. 2019 . http://www.tbus.org.uk/orders.htm

30. Tica S, Filipović S, Živanović P. Bajčetić S. Development of trolleybus passenger transport subsystems in terms of sustainable development and quality of life in cities. International Journal for Traffic \& Transport Engineering 2011; 1(4): 196-205.

31. "TROLLEY project" for the Central Europe; 2014. https://www.interreg-central.eu/Content.Node/2transport-final.pdf

32. Vehicles. Weight parameters and dimensions. Technical requirements and test methods. STB 18772008. Minsk: Belar. State Standards and Certification; 2008.

33. Vignaux GA, Scott JL. Simplifying regression models using dimensional analysis. Australian and New Zealand Journal of Statistics 1999; 41(1): 31-41. https://doi.org/10.1111/1467-842X.00059

34. Yaglinskyi V, Gutyria S, Chanchin A. Parametrical fluctuations of epicycle in wheel gearboxes. British Journal of Applied Science \& Technology 2016; 13(2): 1-8. https://doi.org/10.9734/BJAST/2016/24685

35. Zhang YM. Reliability-based design for automobiles in China. Front. Mech. Eng. 2008; 3(4): 369-376. https://doi.org/10.1007/s11465-008-0064-8

36. Zhang Qi, Mclellan BC, Tezuka T, Ishihara KN. A methodology for economic and environmental analysis of electric vehicles with different operational conditions. Energy 2013; 61: 118-127.

https://doi.org/10.1016/j.energy.2013.01.025

Received 2019-09-18

Accepted 2020-01-03

Available online 2020-01-07

\section{APPENDIX}

Table A - Parameters, characteristics and indicators of the $T$-bus' models perfection

\begin{tabular}{|c|c|c|c|c|c|c|c|c|c|c|c|c|}
\hline \multirow[b]{2}{*}{ № } & \multirow[b]{2}{*}{$\begin{array}{l}\text { Model, manufacturer, } \\
\text { country }\end{array}$} & \multicolumn{7}{|c|}{ Basic technical parameters and characteristics } & \multicolumn{4}{|c|}{ Specific indicators } \\
\hline & & 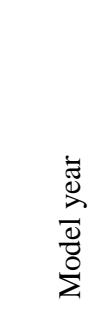 & 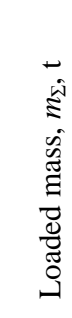 & 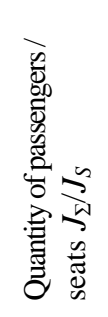 & 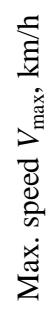 & 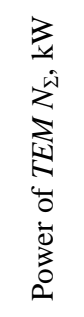 & 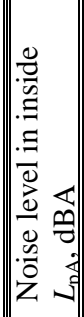 & 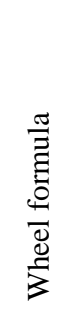 & 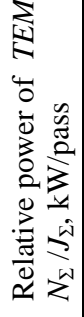 & 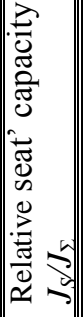 & 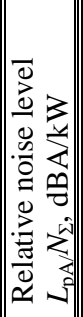 & 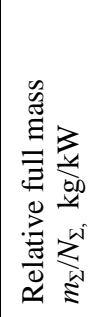 \\
\hline 1 & Tatra T400, Czechoslovakia ${ }^{\mathbf{1 , 4}}$ & 1955 & 17.7 & $80 / 26$ & 60 & $2 \times 65$ & 82 & $6 \times 4$ & 1.62 & (1.33 & .62 & 136.2 \\
\hline 2 & ZiU-5, USSR ${ }^{1,4}$ & 1958 & 17.6 & $90 / 35$ & 60 & 95 & 84 & $4 \times 2$ & 1.06 & .39 & .88 & 185.3 \\
\hline 3 & ZiU-9, USSR ${ }^{1,4}$ & 1966 & 18.4 & $91 / 30$ & 60 & 110 & 84 & $4 \times 2$ & 1.21 & .33 & .76 & 167.3 \\
\hline 4 & $\begin{array}{l}\text { Skoda 14Tr,"Skoda Ostrov", } \\
\text { Czechoslovakia 1, } 4\end{array}$ & 1982 & 17.6 & $100 / 29$ & 60 & 120 & 83 & $4 \times 2$ & 1.20 & .29 & .69 & 146.5 \\
\hline 5 & $\begin{array}{l}\text { MAN NGE 152M17, “Graf \& Stiff”, } \\
\text { Austria 2, 5, }\end{array}$ & 1989 & 27.9 & $142 / 48$ & 65 & 149 & 75 & $6 \times 2$ & 1.10 & .34 & .50 & 187.3 \\
\hline 6 & E902, "New Flyer", Canada 1,4 & 1990 & 18.7 & $96 / 32$ & 60 & 180 & 74 & $4 \times 2$ & 1.46 & .33 & .41 & 103.9 \\
\hline 7 & ZiU-682 GM, Russia ${ }^{1,4}$ & 1990 & 18.1 & $114 / 26$ & 60 & 120 & 84 & $4 \times 2$ & 1.05 & .23 & .70 & 150.8 \\
\hline 8 & $\begin{array}{l}\text { DAC-217E, "ROCAR-DAC", } \\
\text { Romania 2,4 }\end{array}$ & 1990 & 25.7 & $156 / 39$ & 60 & 175 & 84 & $6 \times 2$ & 1.12 & .25 & .48 & 146.9 \\
\hline 9 & $\begin{array}{l}\text { AG 300T, "Van Hool”, } \\
\text { Belgium 2,5 }\end{array}$ & 1995 & 30.0 & $152 / 45$ & 60 & 250 & 74 & $6 \times 2$ & 1.65 & .21 & .30 & 120.0 \\
\hline 10 & $\begin{array}{l}\text { BJD-WG120A,"Huaya", } \\
\text { China 1,5,7 }\end{array}$ & 1996 & 11,9 & $91 / 30$ & 60 & 60 & 75 & $4 \times 2$ & .66 & .33 & 1.25 & 197.5 \\
\hline 11 & UMZ-T2, Dnipro, Ukraine ${ }^{1,4}$ & 1997 & 18.7 & $102 / 27$ & 65 & 130 & 83 & $4 \times 2$ & 1.27 & .26 & .64 & 143.8 \\
\hline 12 & Jelcz M121E, Poland ${ }^{1,5,7}$ & 1997 & 17.5 & $109 / 32$ & 65 & 149 & 75 & $4 \times 2$ & 1.35 & .29 & .50 & 117.5 \\
\hline 13 & $\begin{array}{l}\text { Berkhof Premier AT18, 'VDL Berkhof', } \\
\text { Belgium } 2,5,7\end{array}$ & 1998 & 26.6 & $140 / 45$ & 60 & 170 & 74 & $6 \times 2$ & 1.37 & .37 & .44 & 154.6 \\
\hline
\end{tabular}




\begin{tabular}{|c|c|c|c|c|c|c|c|c|c|c|c|c|}
\hline 14 & \begin{tabular}{|l} 
Ikarus 415.80 T, “Astra Bus”, \\
Romania $\mathbf{1 , 4 , 7}$
\end{tabular} & 1998 & 18.2 & $106 / 26$ & 60 & 176 & 75 & $4 \times 2$ & 1.66 & .25 & .43 & 103.4 \\
\hline 15 & MAZ-103T, Belarus ${ }^{1,4,7}$ & 2000 & $\mid 18.0$ & $108 / 25$ & 65 & 170 & 75 & $4 \times 2$ & 1.57 & .23 & .44 & 105.9 \\
\hline 16 & BKM-32100D, Belarus 1,4,7 & 2000 & 18.0 & $90 / 22$ & 60 & 150 & 75 & $4 \times 2$ & 1.66 & .24 & .50 & 120.0 \\
\hline 17 & $\begin{array}{l}\text { Hess SwissTrolley 2, "Carrosserie Hess", } \\
\text { Switzerland 2, 5,7 }\end{array}$ & 1999 & 28.0 & $121 / 42$ & 65 & 240 & 73 & $6 \times 4$ & 1.98 & .35 & .30 & 116.7 \\
\hline 18 & Bogdan T601.12, Lutsk, Ukraine ${ }^{1,5}$ & 2000 & 17.7 & $100 / 23$ & 55 & 140 & 74 & $4 \times 2$ & 1.40 & .23 & .52 & 126.4 \\
\hline 19 & \begin{tabular}{|l} 
Solaris Trollino 18, \\
"Solaris Bus\&Coach", Poland ${ }^{2,5}$
\end{tabular} & 2001 & 28.0 & $160 / 49$ & 65 & 240 & 75 & $6 \times 2$ & 1.41 & .31 & .31 & 116.7 \\
\hline 20 & \begin{tabular}{|l} 
Solaris Trollino 15, \\
“Solaris Bus\&Coach”, Poland 1, 5,
\end{tabular} & 2002 & 24.0 & $150 / 37$ & 70 & 240 & 74 & $6 \times 2$ & 1.60 & .25 & .31 & 100.0 \\
\hline 21 & Irisbus Civis ETB 18, France-Italy 2,5 , & 2002 & 30.0 & $133 / 33$ & 70 & $4 \times 80$ & 72 & $6 \times 4$ & 2.41 & .25 & .23 & 93.8 \\
\hline 22 & BKM-321, Belarus ${ }^{1,4,7}$ & 2003 & 18.0 & $101 / 26$ & 60 & 180 & 75 & $4 \times 2$ & 1.78 & .26 & .42 & 100.0 \\
\hline 23 & Trolza-5275.03, Russia ${ }^{\mathbf{1 , 5}}$ & 2003 & 18.4 & $120 / 27$ & 60 & 180 & 74 & $4 \times 2$ & 1.50 & .23 & .41 & 102.2 \\
\hline 24 & $\begin{array}{l}\text { Irisbus Sitelis (Skoda 25Tr), } \\
\text { France-Czech Republic 2,5,8 }\end{array}$ & 2003 & 22.35 & $155 / 45$ & 65 & 240 & 73 & $6 \times 2$ & 1.55 & .29 & .30 & 93.1 \\
\hline 25 & $\begin{array}{l}\text { O405NE, "Mercedes-Benz", } \\
\text { Germany 1,4 }\end{array}$ & 2003 & 17.2 & $105 / 35$ & 60 & 149 & 74 & $4 \times 2$ & 1.46 & .33 & .50 & 115.4 \\
\hline 26 & UMZ-E186, Dnipro, Ukraine ${ }^{1,5}$ & 2004 & 18.3 & $116 / 26$ & 60 & 180 & 74 & $4 \times 2$ & 1.55 & .23 & .41 & 101.7 \\
\hline 27 & WG68U, "Yang Zi Jiang”, China ${ }^{1,5}$ & 2005 & 16.5 & $82 / 32$ & 69 & 96 & 74 & $4 \times 2$ & 1.17 & .39 & .77 & 171.9 \\
\hline 28 & E40LFR, 'New Flyer", Canada $1,5,7$ & 2005 & 19.6 & $77 / 31$ & 65 & 240 & 74 & $4 \times 2$ & 3.11 & .40 & .31 & 81.70 \\
\hline 29 & E60LFR, 'New Flyer”, Canada $2,5,7$ & 2005 & 29.0 & $130 / 47$ & 60 & $2 \times 140$ & 74 & $6 \times 4$ & 2.15 & .36 & .26 & 103.6 \\
\hline 30 & $\begin{array}{l}\text { Hess SwissTrolley 3, } \\
\text { "Carrosserie Hess", Switzerland 2,5, }\end{array}$ & 2005 & 28.7 & $142 / 46$ & 60 & $2 \times 160$ & 74 & $6 \times 4$ & 2.25 & .32 & .23 & 89.7 \\
\hline 31 & $\begin{array}{l}\text { WGD61U, "Yang Zi Jiang", } \\
\text { China } \mathbf{1 , \mathbf { 5 } , \mathbf { 8 }}\end{array}$ & 2006 & 16.5 & $80 / 30$ & 69 & 96 & 74 & $4 \times 2$ & 1.20 & .37 & .77 & 171.8 \\
\hline 32 & MAZ-SVARZ 6235, Belarus-Russia ${ }^{1,4}$ & 2007 & 18.0 & $100 / 25$ & 65 & 180 & 75 & $\times 2$ & 1.80 & .25 & .42 & 00.0 \\
\hline 33 & $\begin{array}{l}\text { Skoda 28Tr Solaris, "Skoda Electric", } \\
\text { Czech Republic } \mathbf{1 , 5 , 7}\end{array}$ & 2007 & 24.0 & $135 / 43$ & 65 & 240 & 74 & $6 \times 2$ & 1.78 & .32 & .31 & 100.0 \\
\hline 34 & AKSM-420, Belarus $\mathbf{1 , 5 , 8}$ & 2009 & 18.0 & $7 / 29$ & 60 & 180 & 74 & $4 \times 2$ & 1.85 & .29 & .41 & 100.0 \\
\hline 35 & $\begin{array}{l}\text { ExquiCity 24, "Van Hool", } \\
\text { Belgium 3, 5, }\end{array}$ & 2009 & 34.2 & $145 / 61$ & 67,5 & $2 \times 160$ & 73 & $8 \times 4$ & 2.21 & .39 & .23 & 106.9 \\
\hline 36 & $\begin{array}{l}\text { Hess lighTram 4, "Carrosserie Hess", } \\
\text { Switzerland } \mathbf{3 , 5 , 8}\end{array}$ & 2009 & 37.4 & $200 / 68$ & 65 & $2 \times 160$ & 72 & $8 \times 4$ & 1.6 & .34 & .23 & 116.9 \\
\hline 37 & $\begin{array}{l}\text { Dnipro-T103, UMZ, Dnipro, } \\
\text { Ukraine } \mathbf{1 , \mathbf { 5 } , \mathbf { 8 }}\end{array}$ & 2010 & 18.0 & $100 / 25$ & 65 & 170 & 74 & $4 \times 2$ & 1.70 & .25 & .44 & 105.9 \\
\hline 38 & Bogdan T701.15, Lutsk, Ukra & 2010 & 18.9 & $16 / 32$ & 65 & 175 & 74 & $4 \times 2$ & 1.67 & .28 & .42 & 108.0 \\
\hline 39 & Bogdan T901.10, Lutsk, Ukraine ${ }^{2,5}$ & 2010 & 30.5 & $150 / 38$ & 55 & $2 \times 140$ & 74 & $6 \times 4$ & 1.87 & .25 & .26 & 108.9 \\
\hline 40 & AKSM-43303A, Belarus ${ }^{2,5,7}$ & 2010 & 28.0 & $153 / 48$ & 60 & 240 & 74 & $6 \times 2$ & 1.57 & .31 & .31 & 116.7 \\
\hline 41 & $\begin{array}{l}\text { WG6120BEVHM4, "Yang Zi Jiang”, } \\
\text { China 1, } 5\end{array}$ & 2011 & 8.0 & $76 / 28$ & 69 & 150 & 73 & $4 \times 2$ & 1.97 & .39 & .49 & 120.0 \\
\hline 42 & $\begin{array}{l}\text { WG6100BEVH, "Yang Zi Jiang", } \\
\text { China } \mathbf{1 , 5}, \mathbf{8}\end{array}$ & 2011 & 16.5 & $72 / 30$ & 69 & 165 & 73 & $4 \times 2$ & 2.29 & .42 & .44 & 100.0 \\
\hline 43 & $\begin{array}{l}\text { ExquiCity 18, "Van Hool", } \\
\text { Belgium 2, 5, }\end{array}$ & 2011 & 26.0 & $107 / 42$ & 73 & $2 \times 160$ & 73 & $6 \times 4$ & 3.00 & .39 & .23 & 81.30 \\
\hline 44 & $\begin{array}{l}\text { ssTrolley, } \\
\text { erie Hess", Switzerland } 2, \mathbf{5 , 7}\end{array}$ & 2012 & 27.9 & $142 / 50$ & 60 & $2 \times 160$ & 72 & $6 \times 4$ & 2.25 & .35 & .23 & 87.2 \\
\hline 45 & $\begin{array}{l}\text { CK6122GEV1, “Zhong Tong Bus", } \\
\text { China } \mathbf{1 , 5 , 8}\end{array}$ & 2012 & 8.0 & $96 / 38$ & 69 & 150 & 73 & $4 \times 2$ & 1.56 & .40 & .49 & 120.0 \\
\hline 46 & $\begin{array}{l}\text { CK6123GEV, “Zhong Tong Bus”, } \\
\text { China } \mathbf{1 , 5 , 8}\end{array}$ & 2012 & 18.0 & $107 / 44$ & 69 & 150 & 73 & $4 \times 2$ & 1.40 & .41 & .49 & 120.0 \\
\hline 47 & $\begin{array}{l}\text { Etalon T12110, Chernihiv, } \\
\text { Ukraine } \mathbf{1 , 5 , 8}\end{array}$ & 2012 & 18.0 & $105 / 31$ & 65 & 180 & 73 & $4 \times 2$ & 1.72 & .30 & .40 & 100.0 \\
\hline 48 & Bogdan T701.17, Lutsk, Ukrai & 2013 & 8.0 & $5 / 34$ & 05 & 175 & 73 & $4 \times 2$ & 1.67 & .32 & .41 & 102.8 \\
\hline 49 & $\begin{array}{l}\text { ZK6125BEVG5, "Yu Tong", } \\
\text { China } 1, \mathbf{5 , 8}\end{array}$ & 2013 & 1 & $86 / 38$ & 69 & 150 & 73 & $4 \times 2$ & 1.74 & .44 & .49 & 120.0 \\
\hline 50 & $\begin{array}{l}\text { WG6160DHMS, "Yang Zi Jiang", } \\
\text { China }{ }^{2,5,8}\end{array}$ & 2013 & 28.0 & $153 / 58$ & 69 & 240 & 73 & $6 \times 2$ & 1.57 & .38 & .30 & 116.7 \\
\hline 51 & XT40, "New Flyer", Canada $1,6,9$ & 2014 & 20.3 & $85 / 40$ & 65 & 240 & 72 & $4 \times 2$ & 2.82 & .47 & .30 & 84.60 \\
\hline 52 & XT60, "New Flyer", Canada $2, \mathbf{6 , 8}$ & 2014 & 30.1 & $125 / 61$ & 65 & $4 \times 125$ & 72 & $6 \times 4$ & 4.0 & .49 & .15 & 60.20 \\
\hline 53 & $\begin{array}{l}\text { WG6120BEVHM2, "Yang Zi } \\
\text { Jiang", China } 1,5,8\end{array}$ & 2014 & 18.0 & $92 / 40$ & 69 & 200 & 73 & $4 \times 2$ & 2.17 & .43 & .37 & 90.00 \\
\hline 54 & $\begin{array}{l}\text { Trollino Metrostyle, Solaris/Kiepe } \\
\text { Electric, Poland-Germany } \mathbf{2 , 5 , 8 , 9}\end{array}$ & 2014 & 28.0 & $110 / 44$ & 60 & $2 \times 160$ & 72 & $6 \times 4$ & 2.91 & .4 & .23 & 87.5 \\
\hline 55 & \begin{tabular}{|l} 
EIektron T19101, Lviv, \\
Ukraine-Germany $\mathbf{1 , 5}$
\end{tabular} & 2015 & 18.6 & $106 / 34$ & 65 & 180 & 73 & $4 \times 2$ & 1.70 & .32 & .40 & 103.3 \\
\hline
\end{tabular}


Hutyria S, Chanchin A, Yaglinskyi V, Khomiak Y, Popov V.: Evolution of trolley-bus: directions ...

\begin{tabular}{|c|c|c|c|c|c|c|c|c|c|c|c|c|}
\hline 56 & $\begin{array}{l}\text { Hess SwissTrolley 3/4, Kiepe/MAN, } \\
\text { Germany } \mathbf{2 , 5 , 8}\end{array}$ & 2016 & 27.5 & $123 / 48$ & 65 & $2 \times 160$ & 73 & $6 \times 4$ & 2.6 & .39 & .23 & 85.9 \\
\hline 57 & $\begin{array}{l}\text { Trolza 5265.08 Megapolis, } \\
\text { Russia } \mathbf{1 , 6 , 8 , 9}\end{array}$ & 2016 & 18.0 & $100 / 28$ & 60 & 180 & 73 & $6 \times 2$ & 1.8 & .28 & .41 & 100.0 \\
\hline 58 & $\begin{array}{l}\text { Dnipro-T203, UMZ, Dnipro, } \\
\text { Ukraine } \mathbf{1 , 5 , 8}\end{array}$ & 2016 & 18.0 & $107 / 31$ & 65 & 180 & 73 & $4 \times 2$ & 1.68 & .29 & .40 & 100.0 \\
\hline
\end{tabular}

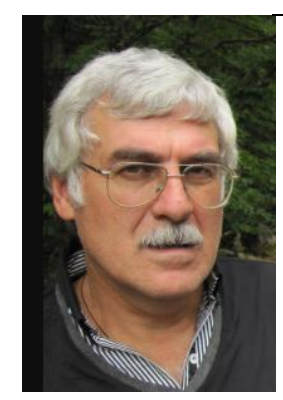

Serhii HUTYRIA defended his doctoral thesis in technical sciences in 2002. Was promoted to full professor of Department of Engineering Science in 2003. Currently works as Director of the Ukrainian-Spanish Institute of Odessa National Polytechnic University. Area of scientific interests - problems of system $C A E$-design and machine' elements system optimization.

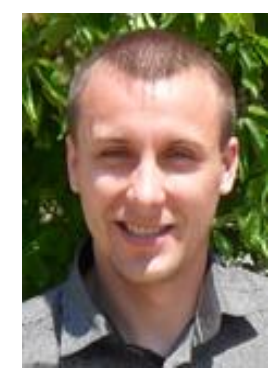

Andrii CHANCHIN obtained his MSc degree in the area of cars and automobile design in 2013 at Odessa National Polytechnic University. Works as assistant at Department of Mechanical Engineering. Area of scientific interests - problems of optimization of gears as a part of traction transmissions of mobile machine's with dual purpose.

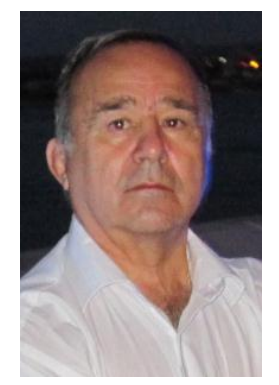

Viktor YAGLINSKYI defended his doctoral thesis in technical sciences in 2012. Works as the head of the Department of the lifting-transport machines and robotics of Odessa National Polytechnic University. Area of scientific interests - dynamics problems of industrial robots and platforms.

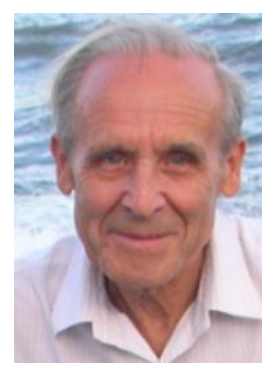

Yuri KHOMIAK defended his $\mathrm{PhD}$ in the Institute of Mechanical Engineering Problems of the National Academy of Sciences of Ukraine. Works at the Institute of Mechanical Engineering of Odessa National Polytechnic University. Area of scientific interests problems of the intense deformed state and fatigue resistance of machine' elements.

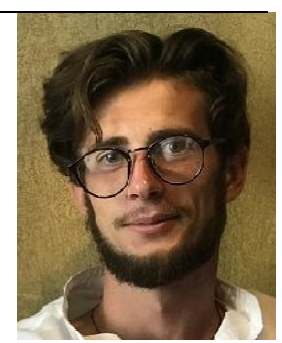

Vadym POPOV, obtained his MS degree in 2018, today is $\mathrm{PhD}$ student at the Department of Mechanical Engineering of Odessa National Polytechnic University. Area of scientific interests problems of fatigue resistance and reliability of hollow axels in structure of trolleybus, railway, and auto- transport. 